\title{
Comparison of bronchopulmonary collaterals and collateral blood flow in patients with chronic thromboembolic and primary pulmonary
} hypertension

\author{
Jiri Endrys, Nasser Hayat, George Cherian
}

\begin{abstract}
Objective-To compare the visualisation of bronchopulmonary collaterals and bronchopulmonary collateral blood flow in patients with chronic thromboembolic pulmonary hypertension and primary pulmonary hypertension.
\end{abstract}

Setting-Referral centre for cardiology at an academic hospital.

Patients-Nine patients with chronic thromboembolic pulmonary hypertension and 17 with primary pulmonary hypertension.

Interventions-Bronchopulmonary collaterals were visualised by selective bronchial arteriography or thoracic aortography. Bronchopulmonary collateral blood flow was estimated by injecting indocyanine green into the ascending aorta and sampling below the mitral valve from the left ventricle.

Results-The degree of pulmonary hypertension was comparable in the two groups. Large bronchopulmonary collaterals were visualised in all the patients with thromboembolic pulmonary hypertension who had bronchial arteriography or aortography or both. None of the primary pulmonary hypertension group studied by aortography had bronchopulmonary collaterals $(P<0.001)$. All the patients with chronic thromboembolic pulmonary hypertension had significant bronchopulmonary collateral blood flow, which was (mean (SD)) $29.8(18.6) \%$ of the systemic blood flow. There was no recordable collateral blood flow in 11 of 15 patients with primary pulmonary hypertension. In the remaining four patients the mean value was $1.1(1.8) \%$ of the systemic blood flow (P $<<0.001)$.

Conclusions-Visualisation of bronchopulmonary collaterals by thoracic aortography or by bronchial arteriography, or the demonstration of an increased bronchopulmonary collateral flow, helps to distinguish patients with chronic thromboembolic pulmonary hypertension from those with primary pulmonary hypertension.

(Heart 1997;78:171-176)

Keywords: pulmonary thromboembolism; primary pulmonary hypertension; bronchial arteries; heart catheterisation
The recognition of chronic thromboembolic obstruction of the central, lobar, and segmental pulmonary arteries resulting in pulmonary hypertension is important since this is potentially curable by pulmonary thromboendarterectomy. ${ }^{1}$ On the other hand, the management of the majority of patients with primary pulmonary hypertension continues to be disappointing despite advances in pharmacotherapy and transplantation..$^{2-5}$ At present, the differentiation of chronic thromboembolic pulmonary hypertension from primary pulmonary hypertension depends mainly on the perfusion-ventilation lung scan and pulmonary angiography. ${ }^{1267}$ The risk of pulmonary angiography in patients with severe pulmonary hypertension and the precautions during angiography need special emphasis. ${ }^{17}$ More recently high resolution computerised tomography, ${ }^{8}$ magnetic resonance imaging, ${ }^{8}$ pulmonary intravascular imaging, ${ }^{9}$ and transoesophageal echocardiography ${ }^{10}$ have been used for the detection of pulmonary thrombi. The separation of thromboembolic pulmonary hypertension from primary pulmonary hypertension is at times difficult, and made more so by the development of in situ thrombosis of the pulmonary arteries in patients with primary pulmonary hypertension. ${ }^{11}$ Many chronic and acute lung diseases are associated with an increase in bronchopulmonary collaterals and bronchial arterial blood flow. ${ }^{12-14}$ Extensive bronchopulmonary collaterals develop to parts of the lung affected by ligation of the pulmonary artery or its branches, ${ }^{1516}$ and after experimental pulmonary embolisation. ${ }^{17}$ In patients with pulmonary embolism, bronchopulmonary collaterals to the affected segments have been demonstrated at necropsy ${ }^{18}$ and during life. ${ }^{19-21}$ This report is based on our observations of bronchopulmonary collaterals and bronchopulmonary collateral blood flow in patients with chronic thromboembolic pulmonary hypertension and primary pulmonary hypertension. This study was not designed to compare the different methods for detecting pulmonary thromboembolism.

\section{Methods}

PATIENT GROUPS

We studied nine patients with severe thromboembolic pulmonary hypertension and 17 with primary pulmonary hypertension. Haemodynamic criteria for inclusion in the
Medicine, Faculty Medicine, Kuwait

$J$ Endrys 
thromboembolic group were pulmonary arterial systolic pressure of $>70 \mathrm{~mm} \mathrm{Hg}$; pulmonary arterial mean pressure of $>45 \mathrm{~mm} \mathrm{Hg}$; and pulmonary vascular resistance index of $>10$ units. After a full clinical assessment, the diagnosis was based on the results of perfusion-ventilation lung scans and pulmonary angiography using previously described criteria. ${ }^{1622-24}$ None of the patients in the thromboembolic group had thromboendarterectomy.

\section{CARDIAC CATHETERISATION AND PULMONARY} ANGIOGRAPHY

Right and left heart catheterisation was performed percutaneously from the groin using standard techniques. Pressures were recorded from the right atrium, right ventricle, pulmonary artery, pulmonary wedge, left ventricle, and aorta, and transseptally from the left atrium. Cardiac output was calculated by dye
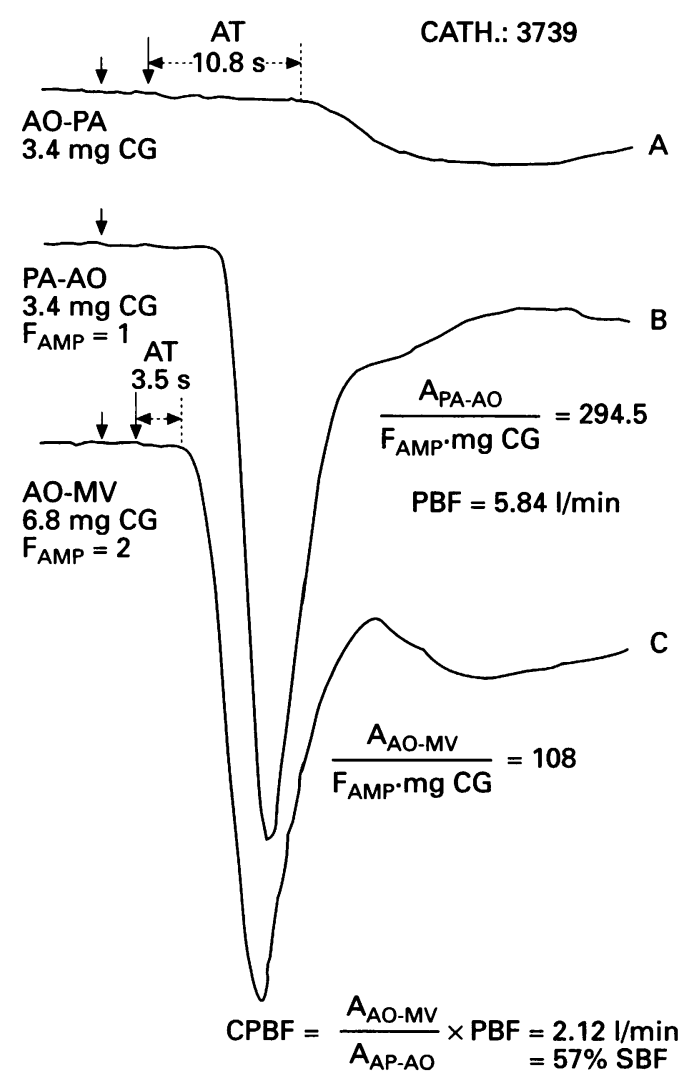

Figure 1 Series of dye dilution curves in patient with chronic thromboembolic pulmonary hypertension (CTEPH) and high bronchopulmonary collateral blood flow (BPCF). Sequence of curves was arranged for graphic reasons. Curve $B$ measured pulmonary blood flow (PBF) by injection of dye into the pulmonary artery (PA) with sampling from the aorta $(A O)$. Curve $C$ quantified the left to right shunt by injection of double the amount of dye into the ascending aorta with double recorder sensitivity and sampling from the left ventricle close to the mitral valve (MV). Ratio of the $C$ curve area divided by $B$ curve area multiplied by pulmonary blood flow (in l/min) gives the BPCF in l/min. Curve $A$ recorded by injection into the ascending aorta $(A O)$ and sampling from main pulmonary artery $(P A)$ excludes patent arterial duct as the cause of the left to right shunt demonstrated by curve $C$. In the absence of $B P C F$, the curve $C$ would have a pattern similar to curve $A$ with long appearance time $(A T)$. CG, Cardiogreen; $F_{A M P}$, amplification factor of the recorder; $\downarrow$, actual injection of dye; $\downarrow$, injection of dye corrected for a delay caused by sampling system; $A_{P A-A O}$, area of the $B$ curve; $A_{A O-M V}$, area of the $C$ curve. dilution techniques. Congenital heart disease, such as patent arterial duct, and other acquired cardiac diseases were excluded. Pulmonary angiography was performed selectively in the right and left pulmonary artery, except in the first few patients.

BRONCHOPULMONARY COLLATERALS

Bronchopulmonary collaterals were assessed by two methods: (1) measurement of bronchopulmonary collateral blood flow using the dye dilution technique; and (2) angiographically by aortography or selective bronchial arteriography or both.

\section{MEASUREMENT OF BRONCHOPULMONARY}

COLLATERAL FLOW

Bronchopulmonary collateral flow was measured by a method based on the principle developed by Cudkowicz, ${ }^{16}$ and used by Nakamura. ${ }^{25}$ We modified this method by using a cuvette densitometer to avoid errors from ear densitometry. Sampling for bronchopulmonary collateral flow was from the left ventricle below the mitral valve, to ensure proper mixing of flow from the right and left pulmonary veins in the left atrium.

Dye curves were recorded using BD5 or BD9 recorders (Kipp and Zonen, Delft, The Netherlands) using a D-402A densitometer (Waters Instruments, Rochester, Minnesota, USA) with the measuring cuvette directly connected to the catheter to reduce the sampling volume. All dye dilution curves were recorded at least twice. A constant rate of blood withdrawal through the cuvette was achieved using a Harvard pump at $40 \mathrm{ml} / \mathrm{min}$ speed (Harvard Apparatus, Southnatick, Massachusetts, USA). Blood was infused back to the patient after each recording. Early on, the curve areas were measured by planimetry, ${ }^{26}$ and in later studies using the Hewlett-Packard catheterisation computer adapted by one of us (JE) for on line measurement of shunts. An example of the dye curves recorded is shown in fig 1 . The first dye curve (B) measured the pulmonary blood flow by injection of indocyanine green (usually $5 \mathrm{mg}$ ) into the pulmonary artery, with sampling from the aorta. The second curve (C) was recorded by injection of double or quadruple amount of dye into the ascending aorta and sampling just below the mitral valve through a transseptal or retrograde catheter, to detect any aorto-pulmonary shunt. In the presence of bronchopulmonary collateral flow, the early recirculation had an appearance time of about three seconds, while the normal recirculation usually started after 10 seconds. The bronchopulmonary collateral flow was calculated as the ratio of the shunt curve area (C) divided by the pulmonary blood flow area (B). This value multiplied by the pulmonary blood flow gives the bronchopulmonary collateral flow in litres per minute. The systemic blood flow (SBF) was derived by subtracting the bronchopulmonary collateral flow (BPCF) from the pulmonary blood flow.

$$
\text { Then, } \frac{\mathrm{BPCF}}{\mathrm{SBF}} \times 100=\mathrm{BPCF} \text { as } \% \text { of } \mathrm{SBF}
$$


Patient groups and haemodynamic results. Values are mean (SD)

\begin{tabular}{|c|c|c|c|c|}
\hline & CTEPH & $P P H$ & & \\
\hline $\operatorname{Men}(n)$ & 5 & 7 & & \\
\hline Women (n) & 4 & 10 & & \\
\hline Age (mean (SD)) years & $45 \cdot 6 \quad(8 \cdot 3)$ & $31 \cdot 2$ & $(12 \cdot 8)$ & $P<0.006$ \\
\hline Systolic & $120.9 \quad(14.5)$ & $117 \cdot 6$ & $(18 \cdot 1)$ & \\
\hline $\begin{array}{l}\text { Diastolic } \\
\text { Mean }\end{array}$ & $\begin{array}{l}79 \cdot 3(6 \cdot 8) \\
94 \cdot 4 \quad(8.9)\end{array}$ & $\begin{array}{l}80 \cdot 8 \\
96 \cdot 6\end{array}$ & $\begin{array}{l}(13 \cdot 6) \\
(15 \cdot 3)\end{array}$ & \\
\hline PA pressure $(\mathrm{mm} \mathrm{Hg})$ & & & & \\
\hline Systolic & $97 \cdot 3 \quad(5 \cdot 0)$ & $91 \cdot 5$ & $(21 \cdot 9)$ & \\
\hline Diastolic & $33.8 \quad(6.4)$ & $40 \cdot 6$ & $(11 \cdot 4)$ & \\
\hline $\begin{array}{l}\text { Mean } \\
\text { LA pressure }(\mathrm{mm} \mathrm{Hg})\end{array}$ & $57 \cdot 7 \quad(8 \cdot 2)$ & $59 \cdot 4$ & $(13 \cdot 7)$ & \\
\hline $\begin{array}{l}\text { LA pressure }(\mathrm{mm} \mathrm{Hg}) \\
\text { Mean }\end{array}$ & $(6.4)$ & $4 \cdot 1$ & $(0.5)$ & \\
\hline $\mathrm{RA}$ pressure $(\mathrm{mm} \mathrm{Hg})$ & & & & \\
\hline Mean & $7 \cdot 6 \quad(2 \cdot 8)$ & $7 \cdot 8$ & $(6 \cdot 2)$ & \\
\hline Cardiac index $\left(1 / \mathrm{min} / \mathrm{m}^{2}\right)$ & $2.02(0.6)$ & $2 \cdot 10$ & $(0 \cdot 7)$ & \\
\hline PVRI (units/m²) & $21.7 \quad(5 \cdot 2)$ & $25 \cdot 0$ & $(11 \cdot 9)$ & \\
\hline BPCF $(1 / \mathrm{min})$ & $0.93(0.49)$ & 0.027 & $(0.045)$ & $P<0.0001$ \\
\hline BPCF (\% of SBF) & $29 \cdot 8 \quad(18 \cdot 6)$ & $1 \cdot 1$ & $(1 \cdot 8)$ & $P<0.0001$ \\
\hline
\end{tabular}

BPCF, bronchopulmonary collateral flow; CTEPH, chronic thromboembolic pulmonary hypertension; LA, left atrium; PA, pulmonary artery; $\mathrm{PPH}$, primary pulmonary hypertension hypertension; LA, left atrium; PA, pulmonary artery; PPH, primary pulmonary hyperte
PVRI, pulmonary vascular resistance index; RA, right atrium; SBF, systemic blood flow.

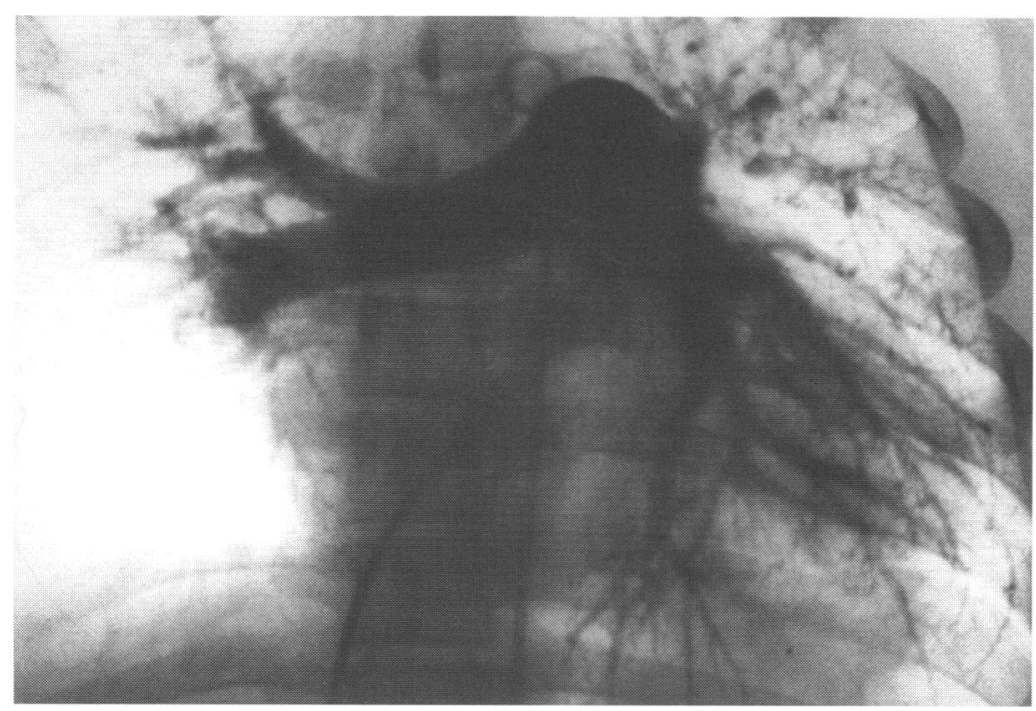

Figure 2 Pulmonary angiogram from a patient with thromboembolic pulmonary hypertension. All segmental branches of the pulmonary artery in the right lower and left upper lobe are completely or subtotally occluded. Subsegmental branches of the right upper lobe and left lower lobe show varying degrees of obstruction. The main and right pulmonary artery are dilated.
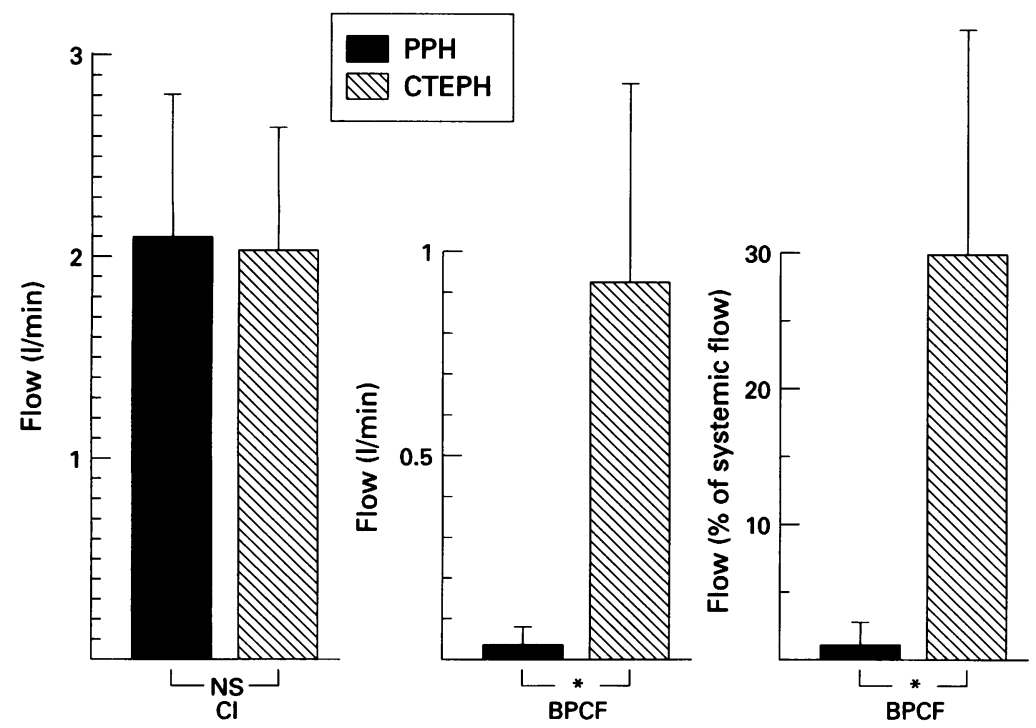

Figure 3 Diagram of flow data showing the cardiac index values (CI) and bronchopulmonary collateral flow (BPCF). The BPCF was minimal in the primary pulmonary hypertension group (PPH) and markedly increased in patients with chronic thromboembolic pulmonary hypertension (CTEPH). ${ }^{\star} P<0.0001$.
STATISTICAL ANALYSIS

The unpaired Student $t$ test was used. Values are given as mean (SD).

\section{Results}

The age and sex distribution and basic haemodynamic data are shown in the table. Patients with thromboembolic pulmonary hypertension were on the average about 15 years older than the group with primary pulmonary hypertension. All patients with thromboembolic pulmonary hypertension had segmental or larger perfusion defects that were normally ventilated, while those with primary pulmonary hypertension had normal or subsegmental inhomogeneity in perfusion. Pulmonary angiography in patients with thromboembolic pulmonary hypertension showed varying combinations of filling defects, abrupt narrowing or cut off of arteries, webs, bands, or lumenal irregularities, as in other reports. In primary pulmonary hypertension there was symmetrical dilatation of proximal and hilar pulmonary arteries with relatively rapid taper and marked peripheral arterial pruning. The pulmonary artery systolic and mean pressures and pulmonary vascular resistance index were raised and similar in patients with primary pulmonary hypertension and thromboembolic pulmonary hypertension (NS). One patient in the primary pulmonary hypertension group did not have pulmonary angiography. This patient had the lowest cardiac index in this report $\left(1.02 \mathrm{l} / \mathrm{min} / \mathrm{m}^{2}\right)$ and the highest right atrial (mean $28 \mathrm{~mm} \mathrm{Hg}$ ), pulmonary artery systolic $(145 \mathrm{~mm} \mathrm{Hg})$, and mean pulmonary artery pressure (95 $\mathrm{mm} \mathrm{Hg}$ ). The pulmonary angiogram of a patient with thromboembolic pulmonary hypertension is shown in fig 2 .

\section{BRONCHOPULMONARY COLLATERAL FLOW}

The bronchopulmonary collateral flow was estimated in eight of the nine patients with thromboembolic pulmonary hypertension and in 15 of the 17 patients with primary pulmonary hypertension. In the remaining three, indocyanine green was not available at the time of cardiac catheterisation. The bronchopulmonary collateral flow, expressed in $1 / \mathrm{min}$ and as a percentage of systemic blood flow, is shown in fig 3. Bronchopulmonary collateral flow was detected in all eight of the patients with thromboembolic pulmonary hypertension in whom the estimation was made. The mean flow was 0.93 (SD 0.49 ) $1 / \mathrm{min}$, or $29 \cdot 8(18 \cdot 6) \%$ of systemic blood flow. There was no detectable bronchopulmonary collateral flow in 11 of the 15 patients with primary pulmonary hypertension in whom the estimation was made. In the remaining four patients, the mean value was $0.027(0.045)$ $1 / \mathrm{min}$, which was $1 \cdot 1(1 \cdot 8) \%$ of systemic blood flow. Thus there was a highly significant difference in bronchopulmonary collateral flow between patients with chronic thromboembolic pulmonary hypertension and patients with primary pulmonary hypertension $(\mathrm{P}<<$ $0.001)$. 
Figure 4 Selective bronchial arteriogram in a patient with thromboembolic pulmonary hypertension (CTEPH). The dilated bronchial artery is clearly seen as well as mesh of small bronchial vessels connected to the pulmonary arterial branches downstream to the embolic occlusion. $\nabla$ bronchial artery; $\rightarrow$, branches of pulmonary artery distal to the occlusion.

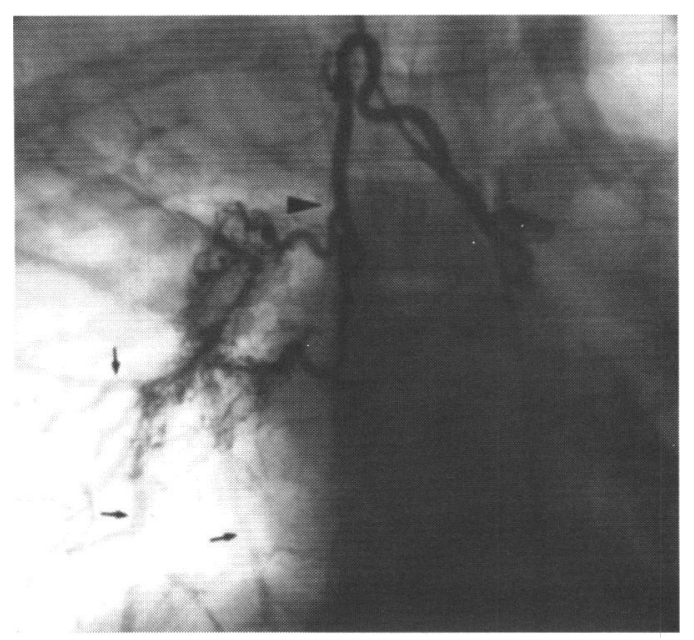

Figure 5 Aortogram in the same patient as in fig 4. Intercostal arteries and a dilated bronchial artery that feeds mesh-like collaterals which faintly opacify the pulmonary artery branches downstream of the embolic occlusion are seen. $\nabla$, bronchial artery.

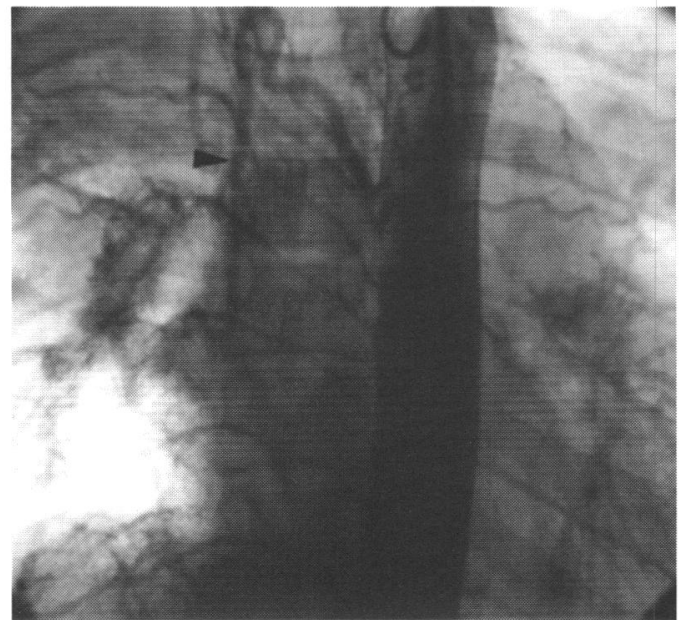

Figure 6 Aortogram in a patient with primary pulmonary hypertension. In spite of well opacified intercostal arteries, no dilated bronchial arteries are seen.

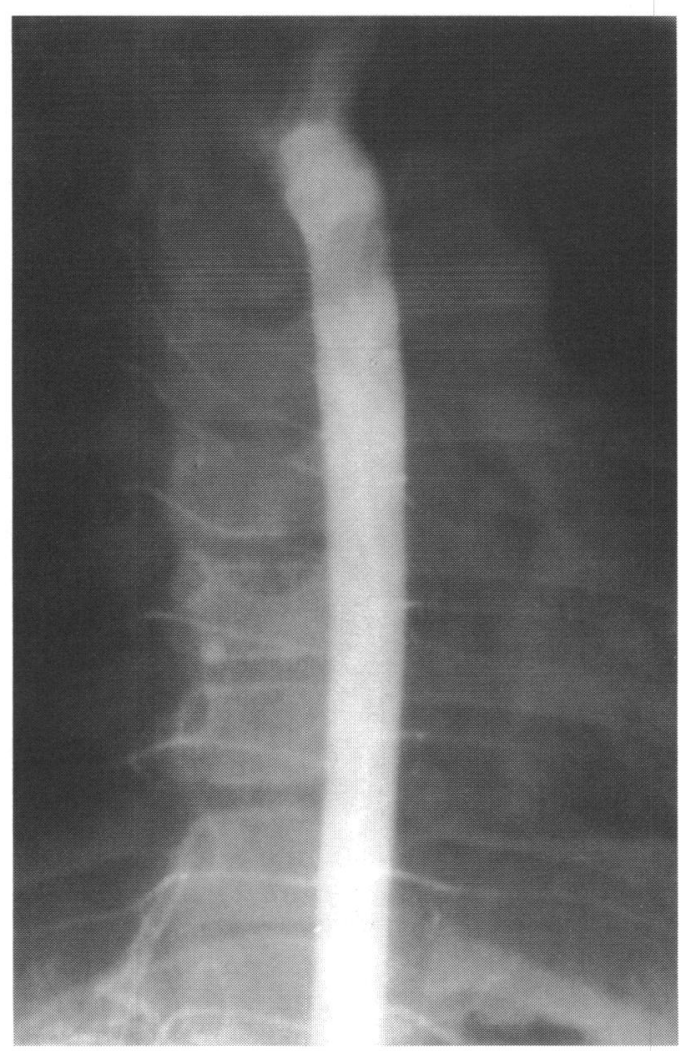

VISUALISATION OF BRONCHOPULMONARY COLLATERALS

Selective bronchial arteriography (fig 4) was done in seven of the nine patients with throm- boembolic pulmonary hypertension and all showed bronchopulmonary collaterals. Aortography was performed in three patients with thromboembolic pulmonary hypertension and this also showed bronchopulmonary collaterals (fig 5). Aortography (fig 6) was done in five patients with primary pulmonary hypertension and bronchopulmonary collaterals were not seen.

\section{Discussion}

Thromboembolic pulmonary vascular disease embraces many syndromes, depending on the segments of the pulmonary arterial tree that are primarily affected. ${ }^{27} 28$ Occlusion of the small muscular arteries and arterioles, which was in the past referred to as microthromboembolism, is now attributed to organised thrombi rather than emboli. ${ }^{28}$ In chronic thromboembolic pulmonary hypertension the obstruction is in the larger proximal and intermediate pulmonary arteries. This type of thromboembolic obstruction can be treated by pulmonary thromboendarterectomy. ${ }^{1}$ Generally by the time the diagnosis is made the clots become organised into the vessel wall, and interpretation of the pulmonary angiogram can be difficult. ${ }^{17}$ The medial hypertrophy of pulmonary arteries in thromboembolic pulmonary hypertension is often mild or absent, suggesting that vasoconstriction does not play an important role. ${ }^{27}$ In proximal thromboembolic pulmonary hypertension the smaller pulmonary arteries and arterioles are generally unaffected, allowing a pressure gradient between the potential bronchopulmonary anastomoses. There is also an initial injury to the lung parenchyma from pulmonary infarction. On the other hand, in primary pulmonary hypertension the predominant vascular lesions are in the small muscular arteries and arterioles. ${ }^{29}$ The changes are bilateral, widespread, uniform, and not confined to a particular segment of the lung. ${ }^{29} 30$ At necropsy in primary pulmonary hypertension there is no embolic source and in one study thromboembolic lesions were present in less than $3 \%$ of small pulmonary arteries. ${ }^{30}$ Fibrinoid necrosis and plexiform lesions, believed to be related to intense vasoconstriction, are regularly observed in advanced stages. $^{2}$

The bronchial arteries, usually two major arteries to each lung arise from the thoracic aorta or an intercostal artery. The right bronchial arteries usually arise from the intercostal arteries, generally the first intercostal. The left bronchial arteries commonly arise directly from the aorta. Rarely the bronchial arteries originate from the internal mammary or coronary arteries and can therefore be missed on aortography. ${ }^{14}$ At the level of the respiratory bronchioles, the bronchial arteries give rise to capillaries which communicate with pulmonary capillaries. ${ }^{29}$ The bronchial veins from the extrapulmonary airway finally drain into the right heart. The bronchial veins from the intrapulmonary airways and lung parenchyma drain through the "bronchopul- 
monary collateral" flow into the left atrium. ${ }^{14}$ Thus sampling from the left ventricle below the mitral valve would detect bronchopulmonary collateral flow. The bronchial arterial blood flow in the human lung is of the order of $1-2 \%$ of the cardiac output. ${ }^{29}$ Many chronic and acute lung diseases are associated with an increase in bronchial blood flow. This has been shown for bronchiectasis and granulomas, pulmonary interstitial fibrosis, bronchogenic carcinoma, pleural disease, asthma, bronchitis, emphysema, and acute conditions like pneumonia and adult respiratory disease syndrome. ${ }^{14}$

Ligation of a pulmonary artery in the dog results in the development of bronchopulmonary collaterals to the affected side, and the collateral blood flow could be as much as one third of the output of the right ventricle. ${ }^{15}$ Malik and Tracy ${ }^{17}$ used beads to embolise the pulmonary circulation to a degree sufficient to increase the pulmonary artery pressure and pulmonary vascular resistance to about three times the normal value. They observed that the bronchial blood flow did not change at five minutes, decreased at six minutes, and was greatly increased to around $300 \%$ at two weeks postembolisation. ${ }^{17}$ Orell and Hultgren $^{18}$ carried out postmortem bronchial arteriography in 28 cases with pulmonary thromboemboli of varying ages. In 18 of the 23 cases with emboli more than two weeks old, there was filling of the pulmonary artery distal to the occlusions through bronchopulmonary collaterals. In this study, bronchopulmonary arterial anastomoses at the level of 1-2 $\mathrm{mm}$ thick peripheral bronchi were the most common. Matsuda ${ }^{21}$ performed bronchial arteriography in 23 patients with documented pulmonary embolism. All 17 patients in the chronic stage with no radiological infiltrates had bronchial to pulmonary arterial collaterals with antegrade filling of the distal pulmonary arteries. By contrast only one out of six had such collateral vessels when studied at a time when radiological infiltrates were still present.

Injection of indocyanine green in the ascending aorta and sampling below the mitral valve will detect an aortopulmonary shunt. None of our patients had a patent arterial duct. Significant bronchopulmonary collateral flow was present in all eight of our patients with thromboembolic pulmonary hypertension in whom the assessment was made. On the other hand there was no detectable bronchopulmonary collateral flow in 11 of 15 patients with primary pulmonary hypertension. In the remaining four patients the flow was small. The difference in bronchopulmonary collateral flow between thromboembolic pulmonary hypertension and primary pulmonary hypertension patients was highly significant (fig 3 ). The cardiac and pulmonary vascular indices were comparable in the thromboembolic and primary pulmonary hypertension patients.

Normal bronchial arteries may be visualised on routine cineangiography when contrast material is injected into the descending thoracic aorta, but bronchopulmonary communi- cations are not seen. In our study, selective bronchial arteriography or aortography showed that all patients with thromboembolic pulmonary hypertension had dilated bronchial arteries and a mesh of bronchopulmonary collaterals. The bronchopulmonary collaterals were seen to fill the pulmonary arterial branches downstream of the site of embolic occlusion. Aortography did not show dilated bronchial arteries or bronchopulmonary collaterals in any of the patients with primary pulmonary hypertension. Selective bronchial arteriography was not performed in patients with primary pulmonary hypertension as they had either undetectable or minimal bronchopulmonary collateral flow.

Pulmonary hypertension per se is clearly not the stimulus for the development of bronchopulmonary collaterals in thromboembolic pulmonary hypertension since the increase in pulmonary artery pressure was equally severe in primary pulmonary hypertension. The development of bronchopulmonary collaterals in several acute and chronic lung conditions suggests that an initial stimulus may be damage to the lung tissue, and such damage is not a feature of primary pulmonary hypertension. Experimental and clinical observations show that the development of bronchopulmonary collaterals takes about 10-14 days after the embolic episode and the collaterals increase with time. ${ }^{171821}$ The short time taken for the collateral development suggests that any difference in the length of survival of patients with thromboembolic versus primary pulmonary hypertension is unimportant. The obstructive pulmonary artery lesions with thromboembolic pulmonary hypertension are patchy and largely spare the small pulmonary arteries and arterioles. ${ }^{27}$ This would allow a pressure flow gradient to develop between the systemic bronchial circulation and the pulmonary circulation distal to the block in the proximal pulmonary arteries, thus encouraging the development of bronchopulmonary collaterals.

\section{CONCLUSIONS}

Large bronchopulmonary collaterals and an increase in collateral flow were found in patients with thromboembolic pulmonary hypertension and not in primary pulmonary hypertension. These bronchopulmonary collaterals can be demonstrated on thoracic aortography without resorting to selective bronchial arteriography or an estimation of collateral blood flow.

This study helps in our understanding of some of the pathophysiological differences between thromboembolic pulmonary hypertension and primary pulmonary hypertension. The use to which this observation is put could depend upon the clinical situation. In the context of thromboembolic and primary pulmonary hypertension, the demonstration of bronchopulmonary collaterals establishes the presence of proximal pulmonary thromboembolism. At present, pulmonary angiography may be considered essential while planning pulmonary thromboendarterectomy. The 
demonstration of bronchopulmonary collaterals by thoracic aortography could be one way of selecting critically ill patients with severe pulmonary hypertension and suspected thromboembolism for pulmonary angiography. The demonstration of bronchopulmonary collaterals is also likely to help in the differentiation of patients with thromboembolic pulmonary hypertension from those with primary pulmonary hypertension and in situ thrombosis. Bronchopulmonary collaterals would not be expected to develop in patients with preexisting primary pulmonary hypertension. However, we did not have any patients in this clinical subset.

We thank Mrs Augustilia G Pinto for her help in the preparation of this manuscript.

1 Moser KM, Auger WR, Fedullo PF, Jamieson SW. Chronic thromboembolic pulmonary hypertension: clinical picture and surgical management. Eur Respir f 1992. 5:334- 42 .

2 Rich S. Primary pulmonary hypertension. Prog Cardiovasc Dis 1988;31:205-38.

3 D'Alonzo GE, Barst RJ, Ayres SM, Bergofsky EH, Brundage BH, Detre KM, et al. Survival in patients with primary pulmonary hypertension: results from a National primary pulmonary hypertension: results from a Nation

4 Uren NG, Oakley CM. The treatment of primary pulmonary hypertension [editorial]. Br Heart $\mathcal{f} 1991 ; 66$ : 119-21.

5 Higenbottam TW, Spiegelhalter D, Scott JP, Fuster V Dinh-Xuan AT, Caine N, et al. Prostacyclin (Epoprostenol) and heart lung transplantation as treatments for severe pulmonary hypertension. Br Heart $f 1993$ 70:366-71.

6 D'Alonzo GE, Bower JS, Dantzker DR. Differentiation of patients with primary and thromboembolic pulmonary hypertension. Chest 1984;85:457-61.

7 Nicod P, Peterson K, Levine M, Dittrich H, Buchbinder $\mathrm{M}$, Chappins $\mathrm{F}$, et al. Pulmonary angiography in severe chronic pulmonary hypertension. Ann Intern Med chronic pulmonary

8 Gefter WB, Hatabu H, Holland GA, Gupta KB, Henschke LI, Palevsky HI. Pulmonary thromboembolism: recent LI, Palevsky HI. Pulmonary thromboembolism: recent developments in diagnosis

9 Ricou F, Nicod PH, Moser KM, Peterson KL. Catheter based intravascular imaging of chronic thromboembolic pulmonary disease. Am $\mathcal{F}$ Cardiol 1991;67:749-52.

10 Pruszezyk P, Pacho R, Chlebus M, Filipecki S, Zielinski J, Torbicki A. Non invasive visualization of pulmonary artery thrombi in patients with suspected pulmonary embolism considered for aggressive therapy. Spiral CT versus transoesophageal echocardiography [abstract]. Eur
Heart $\mathcal{F}$ 1996;17(suppl):525.

11 Moser KM, Fedullo PF, Findbeiner WE, Golden J. Do patients with primary pulmonary hypertension develop extensive central thrombi? Circulation 1995;91:741-5.

12 Liebow AA, Hales MR, Harrison W, Bloomer W, Lindskog GE. The genesis and functional implications of collatera circulation of the lungs. Yale $\mathcal{F}$ Biol Med 1950;22:637-50

13 Endrys J, Kral B, Elias J, Hamet A. Left ventricular overload caused by collateral pulmonary circulation in chronic pneumopathies-myth or reality? Cor Vasa 1981;23:121-5.

14 Deffebach ME, Charan NB, Lakshminarayan S, Butler J. The bronchial circulation. Small, but a vital attribute of the lung. Am Rev Respir Dis 1987;135:463-81.

15 Liebow AA, Hales MR, Bloomer WE, Harrison W, Lindskog GE. Studies of the lung after ligation of the pulmonary artery. II. Anatomical changes. Am $₹$ Pathol pulmonary artery.

16 Cudkowicz L, Abelmann WH, Levinson GE, Katznelson G, Jreissaty RM. Bronchial arterial blood flow. Clin Sci 960;19:1-15.

17 Malik AB, Tracy SE. Bronchovascular adjustments after pulmonary embolism. $\mathcal{F}$ Appl Physiol 1980;49:476-81.

18 Orell SR, Hultgren S. Anastomoses between bronchial and pulmonary arteries in pulmonary thromboembolic disease. Acta Pathol Microbiol Scand 1966;67:322-38.

19 Cabrol C, Cabrol A, Acar J, Gandjbakhch I, Guiraudon G Laughlin L, et al. Surgical correlation of chronic postembolic obstructions of the pulmonary arteries. $f$ Thorac Cardiovasc Surg 1978;76:620-8.

20 Mills SR, Jackson DC, Sullivan DC, Moore AV, Heaston DK, Wolfe WG, et al. Angiographic evaluation of chronic pulmonary embolism. Radiology 1980;136:301-8.

21 Matsuda A. Bronchial arteriography in patients with pulmonary embolism. Chest 1984;85:767-73.

22 Fishmann AJ, Moser KM, Fedullo PF. Perfusion lung scan $v$ pulmonary angiography in evaluation of suspected primary pulmonary hypertension. Chest 1983;84:679-83.

23 D'Alonzo GE, Bower JS, Dantzker DR. Differentiation of patients with primary and thromboembolic pulmonary hypertension. Chest 1984;85:457-61.

24 Anderson G, Reid L, Simon G. The radiographic appearances in primary and thromboembolic pulmonary hypertension. Clin Radiol 1973;24:113-20.

25 Nakamura T, Katori R, Miyazawa K, Ishikawa K, Yamaki M. Kobayashi Y. Aortopulmonary collateral flow in patients with pulmonary disease. Am Rev Respir Dis 1968;98:464-73.

26 Yousof AM, Endrys J, Bicik V. Simple method of measuring dye curve area by planimetry using the half area method. dye curve area by planimetry

27 Wagenwoort CA, Denolin $\dot{H}$ Pulmonary circulationadvances and controversies. Amsterdam: Elsevier, 1989: 18-20.

28 Fishman AP. Pulmonary hypertension. In: Schlant RC, Alexander RW, eds. Hurst's The heart. New York McGraw Hill, 1994:1862-3.

29 Fishman AP. Pulmonary diseases and disorders. New York: McGraw-Hill, 1988:995-6.

30 Anderson EG, Simon G, Reid L. Primary and thromboembolic pulmonary hypertension: a quantitative pathological study. $\mathcal{F}$ Pathol 1973;110:273-93. 